Discussion Paper No. 1116

\title{
REGULATION OF DUOPOLY: MANAGED COMPETITION VS REGULATED MONOPOLIES
}

\author{
Asher Wolinsky ${ }^{*}$ \\ Department of Economics \\ Northwestern University \\ Evanston, IL 60208
}

Version: December 1994

* This is a revised and retitled version of the paper "Regulation of Duopoly Under Asymmetric Information: Prices vs Quantities," dated August 1993. I thank K. Bagwell, R. Braeutigam, R. Porter and W. Rogerson for useful comments. Research support from the U.S.-Israel BSF is gratefully acknowledged. 


\title{
REGULATION OF DUOPOLY: MANAGED COMPETITION VS REGULATED MONOPOLIES
}

\begin{abstract}
This paper discusses the regulation of oligopolistic differentiated product industries. The regulator can control the prices, and impose quantity restrictions, but cannot control effectively the quality choices of the firms. We inquire about the optimal choice of regulatory regime--whether and under what conditions managed competition or segmentation of the market between regulated monopolies achieves better results.

In the spatial duopoly model analyzed here, unhindered competition will generally result in an inefficient allocation. When the regulator knows the technologies, optimal managed competition results in distortions of the quality choice, but an optimal regulated monopolies regime achieves the first best outcome. When the regulator is uncertain about the technologies neither of these methods will yield the first best outcome. The regulated monopolies regime still tends to produce better quality choices, but managed competition tends to be more effective at extracting rents from the firms. The overall comparison depends on some finer details of the environment.
\end{abstract}



REGULATION OF DUOPOLY: MANAGED COMPETITION VS REGULATED MONOPOLIES

\section{Introduction}

This paper discusses the relative performance of two alternative regulatory regimes in a duopolistic differentiated product industry. The two regimes are referred to as managed competition and regulated monopolies respectively. A central feature of the industry under consideration is that there is a quality dimension which due to information or enforcement problems cannot be effectively controlled by the regulator. Consequently, in designing the regulation over dimensions which the regulator can control, the indirect effects on the provision of quality have to be taken into account as well. In the managed competition regime prices are regulated but the firms are allowed to compete over market shares through their quality choices. In the regulated monopolies regime the market is divided into regulated monopoly sub-markets ${ }^{1}$.

The specific model analyzed here is a spatial duopoly model where the two competing firms are located at the endpoints of a unit interval which captures the horizontal differentiation dimension. The firms can compete in prices as well as along a vertical quality dimension. In this environment the total surplus generated by an allocation is fully determined by the manner in which the market is divided between the firms and by the quality levels. Unhindered competition between the firms will generally result in an inefficient allocation which creates some scope for regulation. When the regulator knows the cost functions and can impose lump-sum payments on the firms the two regimes can be unambiguously ranked with respect to their welfare performance. Optimal managed competition creates distortions in the quality choices, while an optimal regulated monopolies regime achieves the 
first best outcome. The superiority of the regulated monopolies regime is not surprising. First, the regulator can impose directly the efficient division of the market. Then, it can adjust each of the prices to induce the efficient quality choices in each of the respective sub-markets. Finally, the optimal distribution of the surplus can be implemented through direct transfers. From this benchmark case the discussion proceeds to show that managed competition might sometimes perform better when the regulatory framework suffers from imperfections. The first imperfection is a limitation on the regulator's power to extract firms' rents through lump-sum payments. In such a case, if the regulator assigns higher weight to consumers' surplus than to firms' profits, it may want to impose relatively low prices in both regimes. Then the competitive pressures under managed competition may create stronger inducements for quality provision and overall this regime might perform better.

Another imperfection is the regulator's uncertainty about the firms' cost functions. It is assumed that, after the regulator decides on policy, but before the firms choose qualities, they learn about each other's costs. The intention is to capture situations in which the regulator's policy is determined for a relatively longer period within which firms will learn relatively quickly about each other. If the regulator places higher weight on consumers' welfare, none of the methods of regulation will yield the first best outcome. To increase consumers' welfare at the expense of firms' rents the regulator will distort the allocations away from their first best levels. The managed competition regime tends to be more effective at transferring rents from the firms to the consumers, while the regulated monopolies regime tends to produce more efficient quality choices. It turns out that either of 
the two methods might perform better: the regulated monopolies regime will still be sometimes superior, but in contrast to the complete information environment, managed competition will also be sometimes superior. With other things equal the latter will tend to happen when the regulator assigns relatively higher weight to consumers' welfare.

This paper is not aimed at discussing a specific industry, and consequently the model and analysis are not tailored to fit the actual details of any particular industry. However, the issues discussed here are of relevance for a number of regulated industries and the following concrete examples might be useful in motivating the discussion. Hospital services are differentiated by geographical location and also have important quality dimensions which are difficult to regulate. Regulation can control only prices, or supplement it by the the imposition of exclusive market areas (which might be the case under future health care programs) and other quantity constraints (an option which is exercised in practice through restrictions on the number of hospital beds). The choice of the regulatory regime affects of course the unmonitored quality dimensions and raises the questions addressed here. Transportation industries offer another example. Competing modes such as railroad and trucking offer differentiated services with important quality dimensions which are hard or impossible to regulate effectively. Both managed competition in the sense of this paper and segmentation of markets among regulated firms, in the form of restrictions on routes and volumes, took place in this industry. The question of whether to assign exclusive market areas or to regulate only prices while allowing competition are also relevant for the public utilities and the telecommunication industries ${ }^{2}$. 
Despite the importance of regulated industries which feature some competition, the literature on regulation has focused mainly on monopolistic industries. Two recent articles on regulation of oligopoly under complete information and in the presence of an unregulated quality dimension like that of the present model are Kamien and Vincent (1991) and Ma and burgess (1993). Some recent articles have also started to address issues in the regulation of oligopolies in uncertain environments. Anton and Yao (1989) consider split award auctions in procurement which is of course a closely related subject. McGuire and Riordan (1991) present a model of split award auction in which the regulator auctions the right of serving the market between two firms with unknown costs and has to decide whether to award the entire market to one of the firms or split it equally between them. The part of the present paper which discuses the regulated monopolies regime resembles their work though it extends it by allowing a whole range of possible market shares and flexible prices. Biglaiser and Ma (1993) consider a spatial duopoly model with similar specifications to the one considered here. In their model the regulated firm acts as a stackelberg leader against its unregulated competitor. Their model differs from the present one in its information structure, the nature of the competition and the main questions they address. Anton and Gertler (1994) consider a spatial duopoly set-up with elastic individual consumers' demands and focus on the tradeoff between market assignment and production allocation. Shleifer (1985) and Auriol and Laffont (1992) discuss other aspects, yardstick competition and sampling effects, which do not arise in present paper.

\section{The Mode1}

The basic model is a familiar duopoly model of spatial product differentiation to which we add a vertical quality dimension as well. A unit 
mass of consumers are distributed uniformly along the unit interval. Two firms, indexed by $i=0,1$, are located at either end. Firm $i(i=0,1)$ sells product $i$ of uniform quality $\mathrm{q}^{i}$ at a uniform price $\mathrm{p}^{\mathrm{i}}$. Each consumer is interested in getting one unit. The surplus derived by a consumer located at $\mathrm{z}$ from getting a unit of product $i=0,1$ is

$$
V+q^{i}-t|z-i|-p^{i}
$$

It is assumed that $V>0$ and $q^{i} \in[0, \infty)$, so that consumers' gross willingness to pay for a unit of $i, V+q^{i}$, is positive even if $q^{i}$ is minimal. The parameter $t$ captures the utility loss ("transportation cost") per unit distance between the brand in question and this consumer's ideal brand.

Faced with prices $\mathrm{p}=\left(\mathrm{p}^{0}, \mathrm{p}^{1}\right)$ and qualities $\mathrm{q}=\left(\mathrm{q}^{0}, \mathrm{q}^{1}\right)$ each consumer will demand a unit from the brand that yields him higher surplus provided it is positive. Let $x^{i}\left(p^{i}, p^{j}, q^{i}, q^{j}\right) \equiv x^{i}(p, q)$ denote the demand for product $i$. (Note that here and in the sequel we shall use un-indexed symbols $p, q$ and $x$ to denote the corresponding two-component vectors). It is possible to distinguish between a "monopoly" region in which the market shares of the firms sum to less than 1 so that $x^{i}$ is the solution to $V+q^{i}-p^{i}-t x^{i}=0$, and a "competitive" region where the entire market is served and $x^{i}$ solves

$$
V+q^{i}-t x^{i}-p^{i}=V+q^{j}-t\left(1-x^{i}\right)-p^{j} .
$$

In the monopoly region the demand is $x^{i}(p, q)=\left(V+q^{0}-p^{0}\right) / t$; in the competitive region it is

$$
x^{i}\left(p^{i}, p^{j}, q^{i}, q^{j}\right)=\left(q^{i}-q^{j}+p^{j}-p^{i}+t\right) / 2 t
$$

The cost function of firm $i, c^{i}\left(x^{i}, q^{i}\right)$, is increasing in both arguments, convex and twice differentiable with $c_{12}^{i} \geq 0$. The profit of firm $i$ is

$$
\pi^{i}(p, q)=p^{i} x^{i}(p, q)-c^{i}\left(x^{i}(p, q), q^{i}\right)
$$

Total (consumers' plus producers') surplus is given by 


$$
s(x, q)=\Sigma\left[x^{i}\left(V+q^{i}-t x^{i} / 2\right)-c^{i}\left(x^{i}, q^{i}\right)\right]
$$

where here and subsequently $\Sigma$ stands for summation over $i=0,1$.

We restrict attention to demand and cost specifications with which the surplus maxima and the equilibria to be considered subsequently are 'interior': the entire market is served, both firms are active and their qualities are positive. This will avoid technical complications which are tangential to the issues of this paper. The assumptions needed to achieve this are that $V$ is sufficiently large, that the marginal cost of each firm at quantity 1 is sufficiently higher than that of the other firm at quantity 0 , and that the marginal cost of quality at level 0 is not too high ${ }^{3}$. Thus, from now on, in the interactive scenarios, the demand will be identified with the "competitive" branch of the demand curve as given in (1). The total surplus is maximized at a configuration in which $x^{i}+x^{j}=1$ and the following first order conditions hold

$$
\begin{aligned}
& \frac{\partial s}{\partial x^{i}} \equiv q^{i}-q^{j}-c_{1}^{i}\left(x^{i}, q^{i}\right)+c j_{1}^{j}\left(x^{j}, q^{j}\right)+t-2 t x^{i}=0 \\
& \frac{\partial s}{\partial q^{i}} \equiv x^{i}-c_{2}^{i}\left(x^{i}, q^{i}\right)=0 \quad i=0,1 .
\end{aligned}
$$

\section{Competition and regulation under full information}

\section{A. Competition}

The firms choose their price-quality combinations, $\left(p^{i}, q^{i}\right)$, simulataneously. An interior Nash equilibrium (in which the entire market is served, both firms are active and qualities are positive) satisfies the following first order conditions.

(6) $\frac{\partial \pi^{i}}{\partial p^{i}} \equiv x^{i}+p^{i}\left(\partial x^{i} / \partial p^{i}\right)-c_{1}^{i}\left(\partial x^{i} / \partial p^{i}\right) \equiv x^{i}-\left(p^{i}-c_{1}^{i}\right) / 2 t=0$ 
(7) $\frac{\partial \pi^{i}}{\partial q^{i}} \equiv\left(p^{i}-c_{1}^{i}\right)\left(\partial x^{i} / \partial q^{i}\right)-c_{2}^{i} \equiv\left(p^{i}-c_{1}^{i}\right) / 2 t-c_{2}^{i}=0$

Condition (6) captures the usual mark-up of price over marginal cost in imperfect competition. It can be rewritten as $\mathrm{p}^{i}-\mathrm{c}_{1}^{i}=2 t \mathrm{x}^{i}$. Substituting this into (7) yields $c_{\frac{1}{2}}=x^{i}$. This means that the equilibrium $q^{i \prime}$ s also maximize the total surplus, $s(x, q)$, given the equilibrium market shares, $x$.

This property of the equilibrium $q^{i \prime} s$ owes to the assumption that consumers have the same valuations of quality. Since the firm can appropriate through its price the incremental surplus of the marginal consumer associated with a quality increment, the uniformity of the valuations implies that it can also appropriate the incremental total surplus. Therefore, the incremental profit profit associated with quality variations coincides with the incremental surplus, and hence the maximizing levels coincide as well. (Spence (1975) shows that a monopoly's quality might be either lower or higher than the optimal level when the quality valuations of marginal consumers differ from those of average ones.)

Despite the optimality of the equilibrium quality, the equilibrium allocation does not necessarily coincide with the surplus maximizing one. This is because, besides proper quality choice, optimality requires an appropriate allocation of the market shares, which in general will not arise under the imperfect competition prevailing here.

Proposition 1: The equilibrium allocation need not maximize total surplus. (I.e., it maximizes total surplus only for special choices of cost functions) Proof: From (6), the competitive market shares satisfy

$$
2 t x^{i} \equiv q^{i}-q^{j}+p^{j}-p^{i}+t=p^{i}-c_{1}^{i}
$$


In contrast, from (4), the optimal market shares satisfy

$$
2 t x^{i}=q^{i}-q^{j}-c_{1}^{i}\left(x^{i}, q^{i}\right)+c x^{j}\left(x^{j}, q^{j}\right)+t
$$

Thus, if the equilibrium $x^{i \prime s}$ are optimal, then

$$
p^{i}-c_{1}^{i}=p^{j}-c_{1}^{j} \text { and hence } x^{i}=x^{j}=1 / 2
$$

The optimality of the equilibrium allocation therefore requires the following two conditions.

$$
\begin{gathered}
c_{2}^{i}\left(1 / 2, q^{i}\right)=1 / 2 \quad i=0,1 \\
q^{i}-q^{j}-c_{1}^{i}\left(1 / 2, q^{i}\right)+c_{1}^{j}\left(1 / 2, q^{j}\right)=0,
\end{gathered}
$$

where (11) is obtained from plugging $x^{i}=1 / 2$ into (9). Now, since (10) uniquely determines the $\mathrm{q}^{\mathrm{i}} \mathrm{s}$, equation (11) holds only for special choice of cost functions but not in general. QED

The intuition behind this result is straightforward. Let $M B^{i}=V+q^{i}-t x^{i}-c_{1}^{i}$. This is the surplus generated by the unit sold to the marginal consumer of product $i$. At the optimum $M B^{i}=M B^{j}$, but it follows from ( 8 ) that at the equilibrium $M B^{i}-M B^{j}=\left(p^{i}-c_{1}^{i}\right)-\left(p^{j}-c_{1}^{j}\right)$. Now, if the cost functions of the two firms are different, in equilibrium the more efficient firm--the one that has a larger market share--also features a larger mark-up. This implies immediately that the allocation of the market shares is inefficient--the market share of the more efficient firm is too small.

Note that one of the special cases for which equations (10) and (11) hold and hence the equilibrium allocation is efficient is when the two firms have identical cost functions. One may object to referring to this case as "special" on the grounds that, in the symmetric model considered here, identical costs may appear natural. The symmetry, however, does not play an important role in the analysis beyond reducing the complexity of the expressions. In a scenario with different products (e.g., railroading vs 
trucking) there is clearly no reason to suppose that the cost functions are identical. In the geographical differentiation scenario, where the case for identical cost functions is more compelling, other sources of asymmetry such as uneven distribution of the consumers over the interval would induce inefficient equilibrium allocation in a similar way ${ }^{5}$

\section{B. Regulation}

The possible sub-optimality of the equilibrium allocation creates a potential role for regulation. The regulator's objective is maximization of a weighted sum of consumers' surplus and firms' incomes with weights 1 and (1- $\alpha)$ respectively. Let $\mathrm{T}=\left(\mathrm{T}^{0}, \mathrm{~T}^{1}\right)$ denote transfers from the consumers via the regulator to the firms. The regulator's objective then is to maximize

$$
\begin{aligned}
w(x, p, q, T) & =\sum\left[x^{i}\left(V+q^{i}-t x^{i} / 2\right)-p^{i} x^{i}-T^{i}\right]+(1-\alpha) \sum\left[\pi^{i}\left(x^{i}, p^{i}, q^{i}\right)+T^{i}\right]= \\
& =s(x, q)-\alpha \sum\left[\pi^{i}\left(x^{i}, p^{i}, q^{i}\right)+T^{i}\right]
\end{aligned}
$$

subject to $\pi^{i}\left(x^{i}, p^{i}, q^{i}\right)+T^{i} \geq 0$. If the regulator's ability to impose transfers is not constrained beyond the need to assure cost coverage, it can simply choose $\mathrm{T}^{i}=-\pi^{i}\left(\mathrm{x}^{\mathrm{i}}, \mathrm{p}^{\mathrm{i}}, \mathrm{q}^{\mathrm{i}}\right)$, and the objective coincides with maximization of the total surplus $s(x, q)$. Thus, in this part the parameter $\alpha$ plays no role, but it will play a role in later parts.

If the regulator can fully control the firms' behavior, it will simply enforce the welfare maximizing qualities and market shares. The basic assumption, however, is that the regulator cannot directly control the quality levels. The idea is that, even if qualities are observable, they might be sufficiently difficult to verify so as to make their enforcement impractical. Therefore, the regulator's problem is to use the instruments that it can control, such as prices and market shares, with the understanding that they will affect the quality levels which are left at the discretion of the firms. 


\section{Managed competition}

In this regime the interaction unfolds in two stages. First, the regulator determines $p=\left(p^{0}, p^{1}\right)$. Then, the firms compete over market shares by simultaneously choosing quality levels, $q^{i}=q^{i}(p)$. The regulator's problem is

$$
\begin{aligned}
& \text { Choose } p \text { to maximize } s(x(p, q(p)), q(p)) \\
& \text { where } q^{i}(p)=\operatorname{Argmax}_{q^{i} \pi^{i}(p, q) \quad i=0,1}
\end{aligned}
$$

The equilibrium qualities, $q^{i}(p)$, satisfy the first order conditions:

$$
\frac{\partial \pi^{i}(p, q)}{\partial q^{i}}=\left[p^{i}-c_{1}^{i}\left(x^{i}, q^{i}\right)\right] / 2 t-c_{2}^{i}\left(x^{i}, q^{i}\right)=0 \quad i=0,1
$$

The first order conditions of problem (13) with respect to $\mathrm{p}^{1}$ and $\mathrm{p}^{2}$ are thus

$$
\Sigma_{i=0,1}\left[\left(p^{i}-c_{1}^{i}\right) \frac{d x^{i}}{d p^{k}}+\left(x^{i}-c_{2}^{i}\right) \frac{\partial q^{i}}{\partial p^{k}}\right]=0 \quad k=0,1
$$

where $\frac{\partial q^{i}}{\partial p^{k}}$ and hence $\frac{d x^{i}}{d p^{k}}=\frac{d x^{i}(p, q(p))}{d p^{k}}=\frac{1}{2 t}\left[\frac{\partial q^{i}}{\partial p^{k}}-\frac{\partial q^{j}}{\partial p^{k}}-1\right]$ are obtained from total differentiation of (14).

Proposition 2: Optimal managed competition need not necessarily achieve the welfare maximizing allocation. (I.e., it achieves this allocation only for certain special choices of cost functions).

Proof: If this allocation were optimal, it would satisfy (5), $x^{i}=c_{2}^{i}$. This together with the fact that $\left(d x^{1} / d p^{i}\right)=-\left(d x^{0} / d p^{i}\right)$ imply via (15) that $p^{0}-c_{1}^{0}=$ $p^{1}-c_{1}^{1}$. From (14) we have $p^{i}-c_{1}^{i}=2 t c_{2}^{\frac{1}{2}}$. Therefore $c_{2}^{0}=c_{2}^{1}=x^{0}=x^{1}=1 / 2$. The first order conditions for the optimality of the allocation, (4) and (5), can be once again written as (10) and (11). As noted in the proof of proposition 1, condition (10) already uniquely determines the $\mathrm{q}^{\mathrm{i}} \mathrm{s}$, and so equation (11) holds only for special choice of cost functions but not in general. QED 
As noted following Proposition 1, in the unregulated equilibrium the more efficient firm features a larger mark-up which implies that its market share is socially suboptimal. To improve this allocation through price regulation, the price differential between the two firms has to be widened: typically the price of the more efficient firm has to be forced downwards and the price of the other firm has to be forced upwards. But this implies that the quality levels will not be optimal with respect to the new market shares which emerge from the competition with imposed prices. Suppose that i's price was forced downwards so that, in the new configuration, $\frac{\partial \pi^{i}}{\partial p^{i}}=x^{i}-\left(p^{i}-c \frac{1}{1}\right) / 2 t>0$. Since the quality choice is unconstrained $\frac{\partial \pi^{i}(p, q)}{\partial q^{i}} \equiv\left(p^{i}-c_{1}^{i}\right) / 2 t-c_{2}^{i}=0$. It follows that, $c_{2}^{\frac{1}{2}<x^{i}}$ which means that $q^{i}$ is suboptimal, given the new market share. Analogously, the quality level of the other firm is distorted upwards.

\section{Regulated monopolies}

In this regime the regulator divides the market between the two firms and regulates them as monopolies in their separate sub-markets. That is, the regulator dictates a partition $x=\left(x^{0}, x^{1}\right), x^{0}+x^{1}=1$, of the interval such that consumers located at $\left[0, x^{0}\right]$ can be served only by firm 0 and the rest only by firm $1^{6}$. The regulator's problem is then

$$
\begin{aligned}
& \text { Choose } x=\left(x^{0}, x^{1}\right) \text { and } p=\left(p^{0}, p^{1}\right) \text { to maximize } s(x, q(x, p)) \\
& \text { where } \\
& \qquad q^{i}\left(x^{i}, p^{i}\right)=\operatorname{Argmax}\left\{p^{i} y^{i}\left(x^{i}, p^{i}, q\right)-c^{i}\left[y^{i}\left(x^{i}, p^{i}, q\right), q\right]\right\} \quad i=0,1 \\
& \qquad y^{i}\left(x^{i}, p^{i}, q^{i}\right)=\operatorname{Min}\left\{x^{i}, \operatorname{Max}\left\{\left(V+q^{i}-p^{i}\right) / t, 0\right]\right\}
\end{aligned}
$$

Note that $y^{i} \leq x^{i}$ is the actual market share of the firm. Though it will not arise as the outcome, in principle, we could have $\mathrm{y}^{\mathrm{i}}<\mathrm{x}^{\mathrm{i}}$, so that some marginal consumers elect not to buy. 
Proposition 3: The optimal regulated monopolies regime attains the welfare maximizing allocation.

Proof: Let $\hat{\mathrm{x}}^{i}$ and $\hat{\mathrm{q}}^{i}$ be the welfare maximizing market shares and qualities, and let $\hat{\mathrm{p}}^{\mathrm{i}}=\mathrm{V}+\hat{\mathrm{q}}^{\mathrm{i}}-t \hat{\mathrm{x}}^{\mathrm{i}}$. The assumptions on cost and demand (see footnote 3 ) imply that $\left[\hat{p}^{i}-c_{1}^{i}\left(\hat{x}^{i}, \hat{q}^{i}\right)\right] / t-c_{2}^{i}\left(\hat{x}^{i}, \hat{q}^{i}\right) \geq 0$. Therefore, $q^{i}\left(\hat{x}^{i}, \hat{p}^{i}\right)=\hat{q}^{i}$ and hence the imposition of $\hat{\mathrm{x}}^{i}$ and $\hat{\mathrm{p}}^{i}$ achieves the surplus maximizing allocation. QED

Note that the regulator can achieve the same allocation by imposing the partition $\left(\hat{x}^{0}, \hat{x}^{1}\right)$ while leaving the prices at the discretion of the firms. In this case, firm $i$ will anyway choose $\hat{p}^{i}$ and hence $\hat{q}^{i}$, since it can capture through the price all the incremental surplus resulting from quality improvements.

Propositions 2 and 3 together establish the superiority of the regulated monopolies regime. This is not surprising, since the regulator has three instruments to address the three dimensions of interest. First, the regulator can impose directly the efficient division of the market. Then, it can adjust each of the prices to induce the efficient quality choices in each of the respective sub-markets. Finally, the optimal distribution of the surplus can be implemented through direct transfers.

This conclusion may not hold when the regulator's ability to extract firms' rents through lump-sum payments is limited. In such a case, if the regulator assigns higher weight to consumers' surplus (i.e., $\alpha>0$ ), it may want to impose relatively low prices in both regimes. Then the competitive pressures under managed competition would create stronger inducements for quality provision and overall this regime might perform better. This point is illustrated by the following example. 
Suppose that the regulator's objective is maximization of consumers' surplus (i.e., $\alpha=1), \sum x^{i}\left(V+q^{i}-t x^{i} / 2-p^{i}\right)$, subject to firms' profitability constraint $\pi^{i}\left(\mathrm{x}^{i}, \mathrm{p}^{\mathrm{i}}, \mathrm{q}^{\mathrm{i}}\right) \geq 0$, and that direct transfers are infeasible. Let $c^{i}\left(x^{i}, q^{i}\right)=11 / 16+\left(x^{i}\right)^{2}+\left(q^{i}\right)^{2}$ up to $x^{i}=0.6$ (beyond which the cost $r i s e s$ very sharp $\left.1 y^{7}\right), V=10$ and $t=1$. Under optimal regulated monopolies regime $x^{0}=x^{1}=1 / 2$ and $\mathrm{p}^{0}=\mathrm{p}^{1}=15 / 8$. The induced qualities are $\mathrm{q}^{0}=\mathrm{q}^{1}=0$ and the resulting consumers' surplus is $V-t / 4-15 / 8=7.875$. Under managed competition with prices $p^{0}=p^{1}=2$ (which are not necessarily the optimal ones) the market shares and qualities will be $x^{0}=x^{1}=1 / 2$ and $q^{0}=q^{1}=1 / 4$. Thus, the firms' costs are covered and consumers' surplus is $V+1 / 4-t / 4-2=8$, which is higher than consumers' surplus under the regulated monopolies regime.

In this example, the optimal prices of the regulated monopolies regime are set at the minimal level that allows cost coverage. The firms have no incentive to provide more than quality 0 , since at this level they already serve their captive markets at the imposed prices. The regulator could induce higher qualities by choosing sufficiently high prices. But the necessary increase in prices will more than offset the contribution of the higher qualities to consumers' surplus. Under managed competition, however, higher prices create stronger incentives for market share expansion and hence intensify the quality competition. For an appropriate choice of prices, the resulting quality increases more than compensate for the price increases necessary to maintain the cost coverage.

\section{Regulation under incomplete information}

This section extends the model to consider another imperfection of the regulatory framework: the regulator's incomplete information about the firms' cost functions. The subsequent discussion in Section 5 points out that the 
benchmark observation on the superiority of the regulated monopolies regime might not hold in this environment.

\section{A. preliminaries}

Cost, profit and welfare: Firm i's cost function, $c^{i}\left(x^{i}, q^{i}, \theta^{i}\right)$, is increasing in all of its arguments, convex and twice differentiable, with nonnegative mixed derivatives. The parameter $\theta^{i} \in[0,1]$ captures firm i's private information at the time in which the regulator chooses its policy. The $\theta^{i \prime} s$ are independent draws from a distribution function $F$ with density $f$ and such that $\mathrm{F} / \mathrm{f}$ is increasing. Also, for each realization of $\theta=\left(\theta^{0}, \theta^{1}\right)$ all previous assumptions on the cost functions hold.

The direct profit of firm i is

$$
\pi^{i}\left(x^{i}, p^{i}, q^{i}, \theta^{i}\right)=p^{i} x^{i}-c^{i}\left(x^{i}, q^{i}, \theta^{i}\right)
$$

The total (consumers' plus producers') surplus is

$$
s(x, q, \theta)=\sum\left[x^{i}\left(V+q^{i}-t x^{i} / 2\right)-c^{i}\left(x^{i}, q^{i}, \theta^{i}\right)\right]
$$

As before, letting $\mathrm{T}=\left(\mathrm{T}^{0}, \mathrm{~T}^{1}\right)$ denote transfers from the consumers via the regulator to the firms, the regulator's objective is to maximize

$$
\begin{aligned}
w(x, p, q, T) & =\sum\left[x^{i}\left(V+q^{i}-t x^{i} / 2\right)-p^{i} x^{i}-T^{i}\right]+(1-\alpha) \sum\left[\pi^{i}\left(x^{i}, p^{i}, q^{i}\right)+T^{i}\right]= \\
& =s(x, q, \theta)-\alpha \sum\left[\pi^{i}\left(x^{i}, p^{i}, q^{i}, \theta^{i}\right)+T^{i}\right]
\end{aligned}
$$

In contrast to the complete information environment, here maximization of (19) is not equivalent to maximization of $s(x, q, \theta)$, since the regulator's imperfect information may limit the appropriation of firms' profits.

The regulatory mechanism: First, the regulator comnits to the relevant schedules: in the managed competition regime it commits to price schedules $\mathrm{p}^{\mathrm{i}}:[0,1]^{2} \rightarrow[0, \infty)$ and transfer functions $\mathrm{T}^{\mathrm{i}}:[0,1] \rightarrow \mathbf{R}$; in the regulated monopolies regime it commits in addition to schedules $x^{i}:[0,1]^{2} \rightarrow[0, \infty)$. Then, the firms send simultaneously reports $\sigma^{i}$ to the regulator, where $\sigma^{i}$ is interpreted as a 
report on $\theta^{i}$. The reports determine the relevant magnitudes: prices $\mathrm{p}(\sigma)=\left(\mathrm{p}^{0}(\sigma), \mathrm{p}^{1}(\sigma)\right)$ and transfers $\mathrm{s}^{8} \mathrm{~T}(\sigma)=\left(\mathrm{T}^{0}\left(\sigma^{0}\right), \mathrm{T}^{1}\left(\sigma^{1}\right)\right)$ in the managed competition regime, or shares $\mathrm{x}(\sigma)=\left(\mathrm{x}^{0}(\sigma), \mathrm{x}^{1}(\sigma)\right)$, prices and transfers in the regulated monopolies regime. Finally, the two firms simultaneously choose their $\mathrm{q}^{i \prime} \mathrm{s}$. Only piecewise continuous schedules are considered. Firms' information: At the reporting stage, the firms do not know each other's $\theta^{\prime} s$, but they are assumed to learn each other's costs in the subsequent quality choice stage. This scenario intends to capture a situation in which the regulatory decisions are made for a relatively long period during which firms learn each other's costs relatively quickly, so that most of their interaction will be under conditions of complete information.

\section{B. Managed competition under incomplete information}

The regulator commits to schedules $\mathrm{p}(\sigma)=\left(\mathrm{p}^{0}, \mathrm{p}^{1}\right)$ and $\mathrm{T}(\sigma)=\left(\mathrm{T}^{0}, \mathrm{~T}^{1}\right)$ leaving qualities and market shares to be determined in the subsequent competition. The regulatory mechanism uses only the firms' first stage information as reflected in their reports $\sigma$, although it is possible to design a mechanism which exploits directly the firms' superior information in the second stage by having them report each other's costs later on. If the regulator can credibly commit to sufficiently harsh punishments when these reports expose cheating, such a mechanism can implement anything that can be implemented in the full information $\operatorname{case}^{9}$. However, for a variety of reasons, like inability to administer retroactive punishments based on non-verifiable information, such a mechanism may not be a viable possibility and the scenario considered here pertains to these cases.

Let $q^{i}(p, \theta)$ denote the equilibrium qualities arising in the competition between the firms, given prices $\mathrm{p}$ and cost parameters $\theta$. 


$$
\mathrm{q}^{i}(\mathrm{p}, \theta)=\operatorname{Argmax}_{\mathrm{q}^{i}} \pi^{i}\left[\mathrm{x}^{i}\left(\mathrm{p}, \mathrm{q}^{\mathrm{i}}, \mathrm{q}^{j}(\mathrm{p}, \theta)\right), \mathrm{p}^{\mathrm{i}}, \mathrm{q}^{\mathrm{i}}, \theta^{\mathrm{i}}\right]
$$

That is, $q(p, \theta)$ satisfy the following first order conditions

$$
\frac{\partial \pi^{i}\left[x^{i}(p, q), p^{i}, q^{i}, \theta^{i}\right]}{\partial q^{i}}=\left[p^{i}-c_{1}^{i}\left(x^{i}, q^{i}, \theta^{i}\right)\right] / 2 t-c_{2}^{i}\left(x^{i}, q^{i}, \theta^{i}\right)=0, \quad i=0,1,
$$

Substitute $q(p, \theta)$ into $x(p, q)$ and then both into (17)-(19) to get reduced-form profit and welfare measures embodying the second stage equilibrium quality choices. $\Pi^{i}(p, \theta)=\pi^{i}\left(x^{i}(p, q(p, \theta)), p^{i}, q^{i}(p, \theta), \theta^{i}\right), \quad s(p, \theta)=s(x(p, q(p, \theta)), q, \theta)$ and $\mathrm{W}(\mathrm{p}, \mathrm{T}, \theta)=\mathrm{w}(\mathrm{x}(\mathrm{p}, \mathrm{q}(\mathrm{p}, \theta)), \mathrm{p}, \mathrm{q}(\mathrm{p}, \theta), \mathrm{T}, \theta)$. The regulator's problem is:

Choose functions $\mathrm{p}$ and $\mathrm{T}$ to maximize $\mathrm{E}_{\theta}[\mathrm{W}(\mathrm{p}(\theta), \mathrm{T}(\theta), \theta)]$ subject to (IC) $\mathrm{E}_{\theta^{j}}\left\{\Pi^{\mathrm{i}}\left[\mathrm{p}\left(\theta^{\mathrm{i}}, \theta^{\mathrm{j}}\right), \theta\right]\right\}+\mathrm{T}^{\mathrm{i}}\left(\theta^{\mathrm{i}}\right) \geq \mathrm{E}_{\theta^{j}}\left\{\Pi^{\mathrm{i}}\left[\mathrm{p}\left(\sigma^{\mathrm{i}}, \theta^{j}\right), \theta\right]\right\}+\mathrm{T}^{\mathrm{i}}\left(\sigma^{\mathrm{i}}\right)$ all $\theta^{\mathrm{i}}, \sigma^{\mathrm{i}}, \mathbf{i}$. (IR) $\quad E_{\theta^{j}}\left\{\Pi^{i}\left\{p\left(\theta^{i}, \theta^{j}\right), \theta\right]\right\}+T^{i}\left(\theta^{i}\right) \geq 0 \quad i=0,1$.

where the (IC) constraint guarantees that each firm reports $\theta^{i}$ truthfully and the (IR) constraint assures that the firms want to participate. The following claim reformulates this problem to make it more amenable to analysis. Its proof is relegated to an appendix.

Claim 4: (i) The regulator's problem is

(22) Choose functions $\mathrm{p}$ and $\mathrm{T}$ to maximize:

$$
\mathrm{E}_{\theta}[\mathrm{W}(\mathrm{p}(\theta), \mathrm{T}(\theta), \theta)]=\int_{0}^{1} \int_{0}^{1}\left[S(p, \theta)-\alpha \sum \frac{F\left(\theta^{\mathrm{i}}\right)}{f\left(\theta^{\mathrm{i}}\right)}\left[\frac{\partial c^{\mathrm{i}}}{\partial q^{\mathrm{i}}} \frac{\partial q^{\mathrm{j}}}{\partial \theta^{\mathrm{i}}}+\frac{\partial c^{\mathrm{i}}}{\partial \theta^{\mathrm{i}}}\right]\right] f\left(\theta^{\mathrm{i}}\right) f\left(\theta^{\mathrm{j}}\right) d \theta^{\mathrm{i}} d \theta^{\mathrm{j}}
$$

Subject to the (IC) constraint:

$$
\int_{0}^{\eta} \int_{0}^{1}\left[\frac{\partial c^{i}}{\partial q^{i}} \frac{\partial q^{j}}{\partial \theta^{i}}+\frac{\partial c^{i}}{\partial \theta^{i}}\right] d F\left(\theta^{j}\right) d \theta^{i} \geq\left.\int_{2}^{\eta} \int_{0}^{1}\left[\frac{\partial c^{i}}{\partial q^{i}} \frac{\partial q^{j}}{\partial \theta^{i}}+\frac{\partial c^{i}}{\partial \theta^{i}}\right]\right|_{p=p\left(\eta, \theta^{j}\right)} d F\left(\theta^{j}\right) d \theta^{i} \text { for all } \eta \text { and } \nu
$$

(ii) The total profit (including the transfer) accruing to firm $i$ when $\theta^{i}=\eta$ is

$$
H^{i}(\eta)=\int_{n}^{1} \int_{0}^{1}\left[\frac{\partial c^{i}}{\partial q^{i}} \frac{\partial q^{j}}{\partial \theta^{i}}+\frac{\partial c^{i}}{\partial \theta^{i}}\right] d F\left(\theta^{j}\right) d \theta^{i}
$$


The expression $\frac{\partial c^{i}}{\partial q^{i}} \frac{\partial q^{j}}{\partial \theta^{i}}+\frac{\partial c^{i}}{\partial \theta^{i}}$ which appears in (22)-(23) consists of a direct cost effect $\frac{\partial c^{i}}{\partial \theta^{i}}$ and an indirect "interactive" effect $\frac{\partial c^{i}}{\partial q^{i}} \frac{\partial q^{j}}{\partial \theta^{i}}$. The latter captures the indirect effect of $\theta^{1}$ on $i^{\prime} s$ profit through its effect on $j$ 's choice of quality. This effect owes to the assumption that, in the quality choice stage, firm $j$ can observe $\theta^{i}$. Total differentiation of (21) yields $\frac{\partial q^{j}}{\partial \theta^{i}} \leq 0$, i.e., a higher $\theta^{i}$ makes firm $i$ less competitive and hence induces $j$ to invest less in its quality. Thus, the interactive effect moderates the rate at which i's profit falls in $\theta^{i}$. This observation will be used later to argue that the competition has a rent reducing effect.

\section{C. Regulated monopolies under incomplete information}

Here the interaction is conceptually simpler than under managed competition, since following the assignment of market shares there is no interaction between the firms. First, the regulator commits to schedules $x^{i}:[0,1]^{2} \rightarrow[0,1], p^{i}:[0,1]^{2} \rightarrow \mathbf{R}$ and $T^{i}:[0,1] \rightarrow \mathbf{R}$. Then, the firms simultaneously send reports $\sigma^{i}$, which determine $\mathrm{x}(\sigma), \mathrm{p}(\sigma)$ and $\mathrm{T}(\sigma)$ through the pre-announced schedules. Finally, the qualities to be determined by the firms.

Let $q^{i}\left(x^{i}, p^{i}, \theta^{i}\right)$ denote $i^{\prime} s$ profit maximizing $q^{i}$, given $x^{i}$, $p^{i}$ and $\theta^{i}$.

$$
\begin{aligned}
& q^{i}\left(x^{i}, p^{i}, \theta^{i}\right)=\operatorname{Argqax}\left\{p^{i} y^{i}\left(x^{i}, p^{i}, q^{i}\right)-c^{i}\left[y^{i}\left(x^{i}, p^{i}, q^{i}\right), q^{i}, \theta^{i}\right]\right\} \quad i=0,1 \\
& \text { where } y^{i}\left(x^{i}, p^{i}, q^{i}\right)=\operatorname{Min}\left\{x^{i}, \operatorname{Max}\left[\left(V+q^{i}-p^{i}\right) / t, 0\right]\right\}
\end{aligned}
$$

Substitute $\mathrm{q}^{i}\left(\mathrm{x}^{\mathrm{i}}, \mathrm{p}^{\mathrm{i}}, \theta^{\mathrm{i}}\right)$ into $(17)-(19)$ to get the reduced-form functions:

$\Pi^{i}\left(x^{i}, p^{i}, \theta^{i}\right)=\pi^{i}\left(p^{i}, q^{i}\left(x, \theta^{i}\right), x^{i}, \theta^{i}\right), S(x, p, \theta)=s(p, q(x, \theta), x, \theta)$ and

$\mathrm{W}(\mathrm{x}, \mathrm{p}, \mathrm{T}, \theta)=\mathrm{w}(\mathrm{p}, \mathrm{q}(\mathrm{x}, \mathrm{p}, \theta), \mathrm{x}, \mathrm{T}, \theta)$. The regulator's problem is

Choose functions $x, p, T$ to maximize $E_{\theta}[W(x(\theta), p(\theta), T(\theta), \theta)]$ subject to

$$
\begin{aligned}
& E_{\theta^{j}}\left\{\Pi^{i}\left[x^{i}\left(\theta^{i}, \theta^{j}\right), p^{i}\left(\theta^{i}, \theta^{j}\right), \theta^{i}\right]\right\}+T^{i}\left(\theta^{i}\right) \geq \\
& \mathrm{E}_{\theta^{j}}\left\{\Pi^{\mathrm{i}}\left[\mathrm{x}^{\mathrm{i}}\left(\sigma^{\mathrm{i}}, \theta^{\mathrm{j}}\right), \mathrm{p}^{\mathrm{i}}\left(\sigma^{\mathrm{i}}, \theta^{\mathrm{j}}\right), \theta^{\mathrm{i}}\right]\right\}+\mathrm{T}^{\mathrm{i}}\left(\sigma^{\mathrm{i}}\right) \text { all } \theta^{\mathrm{i}}, \sigma^{\mathrm{i}}, \quad \mathrm{i}=0,1 . \\
& \mathrm{E}_{\theta^{\mathrm{j}}}\left\{\Pi^{\mathrm{i}}\left[\mathrm{x}^{\mathrm{i}}\left(\theta^{\mathrm{i}}, \theta^{\mathrm{j}}\right), \mathrm{p}^{\mathrm{i}}\left(\theta^{\mathrm{i}}, \theta^{\mathrm{j}}\right), \theta^{\mathrm{i}}\right]\right\}+\mathrm{T}^{\mathrm{i}}\left(\theta^{\mathrm{i}}\right) \geq 0 \quad \mathrm{i}=0,1 .
\end{aligned}
$$


The following claim reformulates the regulator's problem.

Claim 5: (i) The regulator's problem is

(25) Choose $\mathrm{x}, \mathrm{p}$ and $\mathrm{T}$ to maximize

$$
\mathrm{EW}=\int_{0}^{1} \int_{0}^{1}\left[S(\mathrm{x}, p, \theta)-\alpha \sum \frac{F\left(\theta^{\mathrm{i}}\right)}{f\left(\theta^{\mathrm{i}}\right)} \frac{\partial c^{\mathrm{i}}}{\partial \theta^{\mathrm{i}}}\right] f\left(\theta^{\mathrm{i}}\right) f\left(\theta^{\mathrm{j}}\right) d \theta^{\mathrm{i}} d \theta^{\mathrm{j}}
$$

Subject to the (IC) constraint:

$$
\int_{2}^{\eta} \int_{0}^{1} \frac{\partial c^{i}}{\partial \theta^{i}} d F\left(\theta^{j}\right) d \theta^{i} \geq\left.\int_{0}^{\eta} \int_{0}^{1} \frac{\partial c^{i}}{\partial \theta^{i}}\right|_{\mathbf{x}=\mathbf{x}\left(\eta, \theta^{j}\right), \operatorname{pep}\left(\eta, \theta^{j}\right)} d F\left(\theta^{j}\right) d \theta^{i} \quad \text { for all } \eta \text { and } \nu .
$$

(ii) The total profit of firm $i$ when $\theta^{i}=\eta$ is

$$
\mathrm{H}^{\mathrm{i}}(\eta)=\int_{n}^{1} \int_{0}^{1} \frac{\partial c^{i}}{\partial \theta^{i}} d F\left(\theta^{j}\right) d \theta^{i}
$$

The proof is relegated to the appendix. It is important to note that the fact that the regulator controls here both $\mathrm{x}$ and $\mathrm{p}$, whereas under managed competition it controls only $\mathrm{p}$, does not mean that any configuration which is implementable under managed competition can be implemented here as well. Technically, this would be true if problem (25) allowed the regulator not to specify $x$, but this is not the case here. For example, if for each $\theta$ the regulator imposes the $p(\theta)$ of the managed competition and the $x$ resulting in the equilibrium of that scenario, then the resulting qualities will be different (lower) than under managed competition, owing to the lack of competition.

\section{Managed competition or regulated monopolies}

The regulated monopolies regime is preferable in the full information environment because it does not distort the quality choices of the firms away from their first best levels. This will still be true in some cases under 
uninformed regulation. But now, besides quality provision, effective transfer of rents is also important, since under asymmetric information the transfer of rents from firms to consumers cannot be accomplished anymore in a non-

distorting manner. Managed competition might be more effective in extracting rents from the firms under asymmetric information, since to some extent rents would be dissipated by the quality competition.

The expressions for the rents under the two regimes capture the above intuition to some extent. From (23) and (26), when $\theta^{i}=\eta$, firm i's rent is $\int_{0}^{1} \int_{0}^{1}\left[\frac{\partial c^{i}}{\partial q^{i}} \frac{\partial q^{j}}{\partial \theta^{i}}+\frac{\partial c^{i}}{\partial \theta^{i}}\right] d F\left(\theta^{j}\right) d \theta^{i}$ under managed competition, and it is $\int_{h}^{1} \int_{0}^{1} \frac{\partial c^{i}}{\partial \theta^{i}} d F\left(\theta^{j}\right) d \theta^{i}$ under the regulated monopolies regime. The comparison between these expressions is not straightforward, since $c^{i}$ in the first expression is $c^{i}\left(x^{i}[p(\theta), q(p(\theta), \theta)], q^{i}(p(\theta), \theta), \theta^{i}\right)$ while $c^{i}$ in the second expression is $c^{i}\left(x^{i}(\theta), q^{i}\left(x^{i}(\theta), p^{i}(\theta), \theta^{i}\right)\right.$. What $c$ an be said is that, if the market shares and quality levels of managed competition were implemented in the regulated monopolies regime, the informational rents of the firms would be higher. This is because in this case the rents under the two regimes differ by the term $\int_{1}^{1} \int_{0}^{1} \frac{\partial c^{i}}{\partial q^{i}} \frac{\partial q^{j}}{\partial \theta^{i}} d F\left(\theta^{j}\right) d \theta^{i}$ which is negative since $\frac{\partial q^{j}}{\partial \theta^{i}} \leq 0$. The following proposition establishes that the resolution of the tradeoff between better quality provision and more effective rent extraction can go in either direction depending on the weight assigned to consumers' welfare in the regulator's objective.

Proposition 6: (i) For sufficiently small $\alpha$, total welfare under optimal regulated monopolies regime is higher than under optimal managed competition; (ii) For sufficiently large $\alpha$, there are cases in which the reverse is true. Proof: (i) Let $x_{w}^{i}\left(\theta^{i}, \theta^{j}\right)$ and $p_{w}^{i}\left(\theta^{i}, \theta^{j}\right)$ denote the solution to the regulated monopolies problem under complete information. As we know from proposition 3 , 
these magnitudes give rise to the first best allocation. Total differentiation of the appropriate version of condition (4) gives that $x_{w}^{i}\left(\theta^{i}, \theta^{j}\right)$ is nonincreasing in $\theta^{i}$. This together with the IC constraint of (25) and the fact $\frac{\partial c^{i}}{\partial x^{i} \partial \theta^{i}} \geq 0$ imply that $x_{w}^{i}\left(\theta^{i}, \theta^{j}\right)$ is implementable under incomplete information as we11. The total welfare achieved by implementing this schedule is equal to the expected full information first best minus a term capturing the firms' rents multiplied by $\alpha$. Thus, when $\alpha$ is sufficiently small, the total welfare under this scheme would be higher than under the full information managed competition and hence under incomplete information as well.

(ii) Consider the example $c^{i}\left(x^{i}, q^{i}, \theta^{i}\right)=\theta^{i} x^{i}+c\left(x^{i}\right)^{2}+k\left(q^{i}\right)^{2}$, which is fully analyzed in section 6. In this example $\frac{\partial q^{i}(p, \theta)}{\partial \theta^{j}}=-c /\left[t(4 k t)^{2}+8 k c t\right]$, and so managed competition has the potential of reducing the firms' rents. Using the expressions derived in Section 6 , direct calculations for $\theta^{i}$ uniform on $[0,1]$ yield the following observations. For $c=10, t=k=1$ and $\alpha$ near 1 , welfare under managed competition is higher than under the regulated monopolies regime. QED

$\alpha$ near 1 means that the regulator values mainly the consumers' surplus and assigns little value to profits, while $\alpha$ near 0 means that consumers' surplus and firms' profits are essentially weighted equally. It is therefore not surprising that managed competition which is more effective in rent extraction performs better when $\alpha$ is larger.

Recall that, under managed competition, in the quality competition stage firms are more informed about each other's costs than the regulator is when it makes the decisions. As noted earlier, the regulator is precluded from using this information directly in a mechanism that punishes deviators retroactively. In a sense, by letting the firms compete, the regulator indirectly uses their superior information in the later stage. To understand 
how the firms' second stage information works to reduce the rents, consider an alternative scenario in which the firms continue to be uninformed about each other's costs in the quality competition stage as well. Here $q^{i}=q^{i}\left(p, \theta^{i}\right)$ does not depend directly on $\theta^{j}$. Consequently, if $p$ is "revealing" $\left(p\left(\theta^{i}, \theta^{j}\right) \neq p\left(\theta^{i}, \hat{\theta}^{j}\right)\right.$ for all $\theta^{i}$ and $\theta^{j} \neq \hat{\theta}^{j}$ ), then firm $i^{\prime}$ s rent when $\theta^{i}=\eta$ (the counterpart of (23)) is now $\int_{0}^{1} \int_{0}^{1} \frac{\partial c^{i}}{\partial \theta^{1}} d F\left(\theta^{j}\right) d \theta^{i}$. If a revealing price schedule is implementable in both scenarios, then the firms' rents are higher when they remain uninformed (the difference between the above term and (23) is $\left.\int_{n}^{1} \int_{0}^{1} \frac{\partial c^{i}}{\partial q^{i}} \frac{\partial q^{j}}{\partial \theta^{i}} d F\left(\theta^{j}\right) d \theta^{i} \leq 0\right)$. Intuitively, when firm $j$ does not learn the true $\theta^{i}$ directly, firm $i$ has a stronger incentive to exaggerate its report of $\theta^{i}$. This is because, in equilibrium, firm $j$ would infer a higher $\theta^{i}$ and since $\frac{\partial q^{j}}{\partial \theta^{i}} \leq 0$ would choose a lower $q^{j}$ than it would if it knew the true $\theta^{i}$. The lower $q^{j}$ relaxes the competition faced by $i$ and increases its profit. Hence, to be kept truthful, the firms are compensated with larger rents in this scenario and in this sense the firms' second stage information is rent reducing.

\section{A fully solved example}

This section derives closed form solutions for the case ${ }^{10}$

$$
c^{i}\left(x^{i}, q^{i}, \theta^{i}\right)=\theta^{i} x^{i}+c\left(x^{i}\right)^{2}+k\left(q^{i}\right)^{2} \quad \text { where } \quad 4 k t>1 .
$$

System (21) applied to this case yields

$q^{i}(p, \theta)=\left[p^{i}\left(4 k t^{2}+4 k c t+c\right)-p^{j} c(4 k t-1)-4 k c t^{2}-2 c^{2}-\left(4 k t^{2}+c\right) \theta^{i}-c \theta^{j}\right] /\left[t(4 k t)^{2}+8 k c t\right]$

Consider first the complete information case. Let the subscripts $c, w$ and $m$ refer to unhindered competition, welfare maximum and managed competition respectively. Let $A=\left[(4 k t)^{2}+2 k t-1+4 k c\right]$. From (6)-(7), (4)-(5) and (15)

$$
\begin{array}{ll}
\mathrm{q}_{c}^{i}=\frac{1}{4 k}+\frac{\theta^{j}-\theta^{i}}{12 k t+8 k c-2} ; \quad \mathrm{p}_{c}^{i}=\theta^{i}+c+t+\frac{2 k(t+c)\left(\theta^{j}-\theta^{i}\right)}{6 k t+4 k c-1} ; \quad x_{c}^{i}=\frac{1}{2}+\frac{k\left(\theta^{j}-\theta^{i}\right)}{6 k t+4 k c-1} . \\
q_{w}^{i}=\frac{1}{4 k}+\frac{\left(\theta^{j}-\theta^{i}\right)}{4 k t+8 k c-2} ; \quad p_{w}^{i}=\theta^{i}+c+\frac{2 c k\left(\theta^{j}-\theta^{i}\right)}{2 k t+4 k c-1} ; & x_{w}^{i}=\frac{1}{2}+\frac{k\left(\theta^{j}-\theta^{i}\right)}{2 k t+4 k c-1} .
\end{array}
$$




$$
\begin{gathered}
\mathrm{q}_{m}^{\mathrm{i}}=\frac{1}{4 k}+\frac{\theta^{\mathrm{j}}-\theta^{\mathrm{i}}}{2 A} ; \quad \mathrm{p}_{\mathrm{m}}^{\mathrm{i}}=c+\theta^{\mathrm{i}}+t+\left[\frac{2 k t^{2}+c}{(t+2 c) A}+\frac{c}{t+2 c}\right]\left(\theta^{j}-\theta^{\mathrm{i}}\right) ; \\
\mathrm{x}_{\mathrm{m}}^{\mathrm{i}}=\frac{1}{2}+\left[\frac{(4 k t)^{2}-2 k t+4 k c}{2(t+2 c) A}\right]\left(\theta^{\mathrm{j}}-\theta^{\mathrm{i}}\right) .
\end{gathered}
$$

From Proposition 3, the regulated monopolies regime yields $x_{w}^{1}$ and $q_{w}^{i}$ as well. If $i$ is the more efficient firm, $\theta^{i}<\theta^{j}$, then $x_{c}^{i}<x_{m}^{i}<x_{w}^{i}$. That is, i's market share in the unhindered competition is too small from a welfare point of view. Managed competition improves the allocation in this respect by inducing a market share $x_{m}^{i}$ larger than $x_{c}^{i}$ (though still smaller than $x_{w}^{i}$ ), but this comes at the expense of distorting the provision of quality. Under unhindered competition $q_{c}^{i}$ is optimal given $x_{c}^{i}$, which means $q_{c}^{i}=x_{c}^{i} / 2 k$. Under managed competition, however, i's quality is suboptimal, $q_{m}^{i}<x_{m}^{i} / 2 k$, while the quality of the less efficient firm is too high given its share.

Consider next the incomplete information environment. Let the subscript "um" (uninformed managed competition) index the solution to problem (22).

$\mathrm{p}_{\mathrm{um}}^{\mathrm{i}}=c+\theta^{\mathrm{i}}+t+\left[\frac{2 k t^{2}+c}{(t+2 c) A}+\frac{c}{t+2 c}\right]\left(\theta^{j}-\theta^{\mathrm{i}}\right)+\alpha \frac{2 k t^{2}+c}{(t+2 c) A}\left[\frac{2 k c t+4 k c^{2}}{t\left((4 k t)^{2}+8 k c\right)}+4 k t-1\right]\left[\frac{F\left(\theta^{\mathrm{i}}\right)}{f\left(\theta^{\mathrm{j}}\right)}-\frac{F\left(\theta^{j}\right)}{f\left(\theta^{j}\right)}\right]$

$\mathrm{q}_{\mathrm{um}}^{\mathrm{i}}=\frac{1}{4 k}+\frac{\theta^{j}-\theta^{\mathrm{i}}}{2 A}+\alpha\left[\frac{k c t+2 k c^{2}}{t A\left((4 k t)^{2}+8 k c\right)}+\frac{4 k t-1}{2 A}\right]\left[\frac{F\left(\theta^{\mathrm{i}}\right)}{f\left(\theta^{\mathrm{i}}\right)}-\frac{F\left(\theta^{j}\right)}{f\left(\theta^{j}\right)}\right]$

$\mathrm{x}_{\mathrm{um}}^{\mathrm{i}}=\frac{1}{2}+\left[\frac{(4 k t)^{2}-2 k t+4 k c}{2(t+2 c) A}\right]\left(\theta^{\mathrm{j}}-\theta^{\mathrm{i}}\right)+\frac{\alpha(4 k t-1)}{2(t+2 c) A}\left[\frac{2 k c t+4 k c^{2}}{t\left((4 k t)^{2}+8 k c\right)}+4 k t-1\right]\left[\frac{F\left(\theta^{j}\right)}{f\left(\theta^{\mathrm{j}}\right)}-\frac{F\left(\theta^{\mathrm{j}}\right)}{f\left(\theta^{\mathrm{j}}\right)}\right]$

$q_{u m}^{i}, p_{u m}^{i}, x_{u m}^{i}$ differ from their perfect information counterparts, $q_{m}^{i}, p_{m}^{i}$, $\mathrm{x}_{\mathrm{m}}^{\mathrm{i}}$ by a term which depends on $\frac{F\left(\theta^{\mathrm{i}}\right)}{f\left(\theta^{\mathrm{i}}\right)}-\frac{F\left(\theta^{\mathrm{j}}\right)}{f\left(\theta^{j}\right)}$. This term reflects the tradeoff between total surplus generation and the appropriation of rents from the firms. Since $F / f$ is an increasing function and $4 k t>1, \theta^{i}<\theta^{j}$ implies that $p_{u m}^{i}<$ $p_{m}^{i}$ and $x_{u m}^{i}>x_{m}^{i}$ while $p_{u m}^{j}>p_{m}^{j}$ and $x_{u m}^{j}<x_{m}^{j}$. Since $x_{m}^{i}<x_{w}^{i}$, it is possible that $x_{u m}^{i}$ 
will be closer to $x_{w}^{i}$ than $x_{m}^{i}$ is. But this does not mean of course that uninformed regulation yields better allocations. On the contrary, the efficiency gains from a larger market share are outweighed by a more significant distortion of the quality: $q_{u m}^{i}$ is lower than $q_{m}^{i}$ which is already suboptimal even relative to a smaller share. The source of this added distortion is the regulator's interest in transferring rents of the firms to consumers: a relatively low price for the lower cost firm, reduces the profitability of the higher cost firm and hence the informational rents. Let "ur" index the solution for uninformed regulated monopolies regime.

$$
\begin{aligned}
& \mathrm{x}_{\mathrm{ur}}^{\mathrm{i}}=\frac{1}{2}+\frac{k\left(\theta^{\mathrm{j}}-\theta^{\mathrm{i}}\right)}{2 k t-1+4 k c}+\frac{\alpha k}{2 k t-1+4 k c}\left[\frac{F\left(\theta^{\mathrm{j}}\right)}{f\left(\theta^{\mathrm{j}}\right)}-\frac{F\left(\theta^{\mathrm{i}}\right)}{f\left(\theta^{\mathrm{i}}\right)}\right] \\
& \mathrm{q}_{\mathrm{ur}}^{\mathrm{i}}=\frac{1}{4 k}+\frac{\theta^{j}-\theta^{i}}{4 k t-2+8 k c}+\frac{\alpha}{4 k t-2+8 k c}\left[\frac{F\left(\theta^{\mathrm{i}}\right)}{f\left(\theta^{\mathrm{i}}\right)}-\frac{F\left(\theta^{j}\right)}{f\left(\theta^{j}\right)}\right]
\end{aligned}
$$

From (24) $p_{u r}^{i}=V+q_{u r}^{i}-t x_{u r}^{i}$. If $\theta^{i}<\theta^{j}$, then $x_{u r}^{i}>x_{w}^{i}$. Here too the source of the distortion is the regulator's interest in transferring rents from the firms to consumers. A relatively larger share for the lower cost firm, reduces the informational rents. As in the complete information regime, $q_{u r}^{i}$ is optimal given $x_{u r}^{i}$. Therefore, the welfare losses are just due to the distortion of the allocation of market shares.

\section{Conclusion}

In regulating oligopolies the regulator has to decide on the framework within which the interaction will take place. Two natural alternative regulatory approaches were examined above: managed competition and the regulated monopolies. When the regulator is completely informed, the latter regime performs better in implementing the desired combination of market shares and quality levels. So, when the distribution of the surplus is not an 
issue, this regime generates higher welfare. But when the regulator assigns higher weight to consumer surplus and its ability to make direct transfers between the firms and the consumers is limited, managed competition would sometimes perform better. When the regulator is incompletely informed but firms are better informed about each other than the regulator, the regulated monopoly regime might still be more effective in quality provision but managed competition is more effective in transferring rents from the firms to consumers. Either of regimes might perform better. When consumers' surplus is weighted relatively heavily in the regulator's objective, managed competition would tend to perform better. 


\section{Appendix}

\section{Proof of Claim 4:}

Let $h^{i}\left(\sigma^{i}, \theta^{i}\right)$ denote firm i's expected income when it reports $\sigma^{i}$ while its true parameter is $\theta^{i}$, provided that firm $j$ reports truthfully,

$$
h^{i}\left(\sigma^{i}, \theta^{i}\right)=E_{\theta^{j}}\left\{\Pi^{i}\left[p\left(\sigma^{i}, \theta^{j}\right), \theta\right]\right\}+T^{i}\left(\sigma^{i}\right),
$$

and let $H^{i}\left(\theta^{i}\right)=h^{i}\left(\theta^{i}, \theta^{i}\right)$. The regulator's problem is

$$
\text { Choose functions } \mathrm{p} \text { and } \mathrm{T} \text { to maximize } \mathrm{E}_{\theta}[\mathrm{W}(\mathrm{p}(\theta), \mathrm{T}(\theta), \theta)]
$$

Subject to

$$
\begin{array}{ll}
\text { (IC) } & \mathrm{h}^{\mathrm{i}}\left(\theta^{\mathrm{i}}, \theta^{\mathrm{i}}\right) \geq \mathrm{h}^{\mathrm{i}}\left(\sigma^{\mathrm{i}}, \theta^{\mathrm{i}}\right) \text { all } \theta^{\mathrm{i}}, \sigma^{\mathrm{i}}, \quad \mathrm{i}=0,1 . \\
\text { (IR) } & \mathrm{h}^{\mathrm{i}}\left(\theta^{\mathrm{i}}, \theta^{\mathrm{i}}\right) \geq 0 \quad \mathrm{i}=0,1 .
\end{array}
$$

The following claim will allow to reformulate problem (Al).

Claim Al: (i) If the functions $p$ and $T$ satisfy $I C$ and if $p$ is piecewise continuous, then $\mathrm{H}^{\mathrm{i}}$ is differentiable almost everywhere and

$$
\mathrm{H}^{\mathrm{i}}(\eta)=\mathrm{H}^{\mathrm{i}}(1)+\int_{0}^{1} \int_{0}^{1}\left[\frac{\partial c^{i}}{\partial q^{i}} \frac{\partial q^{j}}{\partial \theta^{i}}+\frac{\partial c^{i}}{\partial \theta^{i}}\right] d F\left(\theta^{j}\right) d \theta^{i}
$$

(ii) The IC constraint in (A1) is equivalent to: For all $\eta$ and $\nu$,

$$
\int_{2}^{n} \int_{0}^{1}\left[\frac{\partial c^{i}}{\partial q^{i}} \frac{\partial q^{j}}{\partial \theta^{i}}+\frac{\partial c^{i}}{\partial \theta^{i}}\right] d F\left(\theta^{j}\right) d \theta^{i} \geq\left.\int_{0}^{\eta} \int_{0}^{1}\left[\frac{\partial c^{i}}{\partial q^{i}} \frac{\partial q^{j}}{\partial \theta^{i}}+\frac{\partial c^{i}}{\partial \theta^{i}}\right]\right|_{p=p\left(\eta, \theta^{j}\right)} d F\left(\theta^{j}\right) d \theta^{i}
$$

(iii) The IR constraint in (A1) is equivalent to $H^{i}(1) \geq 0$.

Proof of Claim Al: Part (i): Let $C^{i}\left(p, \theta^{i}, \theta^{j}\right)=c^{i}\left[x^{i}[p, q(p, \theta)], q^{i}(p, \theta), \theta^{i}\right]$. That is, $C^{i}\left(p, \theta^{i}, \theta^{j}\right)$ is the cost incurred by $i$ when the prices are $p$ and the cost parameters are $\theta=\left(\theta^{\mathrm{i}}, \theta^{\mathrm{j}}\right)$. Observe that

$$
\begin{gathered}
\mathrm{h}^{\mathrm{i}}(\eta, \eta)-\mathrm{h}^{\mathrm{i}}(\eta, \nu)= \\
\left.\int_{\theta^{1}}^{1} \frac{p^{\mathrm{i}}}{2 t}\left[q^{\mathrm{i}}\left(p, \eta, \theta^{\mathrm{j}}\right)-q^{\mathrm{i}}\left(p, \nu, \theta^{\mathrm{j}}\right)-\left(q^{\mathrm{j}}\left(p, \theta^{\mathrm{j}}, \eta\right)-q^{\mathrm{j}}\left(p, \theta^{\mathrm{j}}, \nu\right)\right)\right]-\left[C^{\mathrm{i}}\left(p, \eta, \theta^{\mathrm{j}}\right)-C^{\mathrm{i}}\left(p, \nu, \theta^{\mathrm{j}}\right)\right]\right\} d F\left(\theta^{\mathrm{j}}\right)
\end{gathered}
$$


where $p=p\left(\eta, \theta^{j}\right)$. Similarly, $h^{i}(\nu, \eta)-h^{i}(\nu, \nu)$ is given by the same expression but with $\mathrm{p}=\mathrm{p}\left(\nu, \theta^{\mathrm{j}}\right)$.

It follows from the IC constraint that

$\mathrm{h}^{\mathrm{i}}(\eta, \eta)-\mathrm{h}^{\mathrm{i}}(\eta, \nu) \geq \mathrm{H}^{\mathrm{i}}(\eta)-\mathrm{H}^{\mathrm{i}}(\nu) \geq \mathrm{h}^{\mathrm{i}}(\nu, \eta)-\mathrm{h}^{\mathrm{i}}(\nu, \nu)$

Dividing through by $\eta-\nu$ and taking the limits of the RHS and LHS as $\nu$ approaches $\eta$ we get that where $\mathrm{p}$ is continuous at $\eta$, these limits are equal.

Therefore, $\mathrm{H}^{\mathrm{i}}$ is differentiable at $\eta$ and the derivative is equal to these limits,

$$
\begin{aligned}
\frac{d H^{i}(\eta)}{d \eta}=\int_{0}^{1}\left[\frac{1}{2 t}\right. & {\left.\left[p^{i}-\frac{\partial c^{i}}{\partial x^{i}}\right]\left[\frac{\partial q^{i}}{\partial \theta^{i}}-\frac{\partial q^{j}}{\partial \theta^{i}}\right]-\frac{\partial c^{i}}{\partial q^{i}} \frac{\partial q^{i}}{\partial \theta^{i}}-\frac{\partial c^{i}}{\partial \theta^{i}}\right] d F\left(\theta^{j}\right)=-\int_{0}^{1}\left[\frac{1}{2 t}\left(p^{i}-\frac{\partial c^{i}}{\partial x^{i}}\right) \frac{\partial q^{j}}{\partial \theta^{i}}+\frac{\partial c^{i}}{\partial \theta^{i}}\right] d F\left(\theta^{j}\right) } \\
& =-\int_{0}^{1}\left[\frac{\partial c^{i}}{\partial q^{i}} \frac{\partial q^{j}}{\partial \theta^{i}}+\frac{\partial c^{i}}{\partial \theta^{i}}\right] d F\left(\theta^{j}\right)
\end{aligned}
$$

where $p=p\left(\eta, \theta^{j}\right), q=q\left(p, \eta, \theta^{j}\right)$ and $\theta^{i}=\eta$. Expression (A2) is now obtained by integration.

Part (ii): IC is equivalent to

$\mathrm{H}^{\mathrm{i}}(\nu) \equiv \mathrm{h}^{\mathrm{i}}(\nu, \nu) \geq \mathrm{h}^{\mathrm{i}}(\eta, \nu)=\mathrm{h}^{\mathrm{i}}(\eta, \eta)-\left[\mathrm{h}^{\mathrm{i}}(\eta, \eta)-\mathrm{h}^{\mathrm{i}}(\eta, \nu)\right] \equiv \mathrm{H}^{\mathrm{i}}(\eta)-\left[\mathrm{h}^{\mathrm{i}}(\eta, \eta)-\mathrm{h}^{\mathrm{i}}(\eta, \nu)\right]$,

which is in turn equivalent to

$\mathrm{H}^{\mathrm{i}}(\nu)-\mathrm{H}^{\mathrm{i}}(\eta) \geq \mathrm{h}^{\mathrm{i}}(\eta, \eta)-\mathrm{h}^{\mathrm{i}}(\eta, \nu)$.

From (A2), $\mathrm{H}^{\mathrm{i}}(\nu)-\mathrm{H}^{\mathrm{i}}(\eta)$ is equal to the LHS of (A3). By direct derivation,

$\mathrm{h}^{\mathrm{i}}(\eta, \eta)-\mathrm{h}^{\mathrm{i}}(\eta, \nu)$ is equal to the RHS of (A3).

$\operatorname{Part}(\mathrm{iii}): \mathrm{h}^{\mathrm{i}}\left(1, \theta^{\mathrm{i}}\right)-\mathrm{H}^{\mathrm{i}}(1)=\mathrm{E} \theta^{\mathrm{j}}\left\{\Pi^{\mathrm{i}}\left[\mathrm{p}\left(1, \theta^{\mathrm{j}}\right), \theta\right]-\Pi^{\mathrm{i}}\left[\mathrm{p}\left(1, \theta^{j}\right), 1, \theta^{j}\right]\right\}=$

$$
\int_{0}^{1}\left[\int_{n}^{1} \frac{\partial \Pi^{i}\left(p\left(1, \theta^{j}\right), \theta\right)}{\partial \theta^{i}} d \theta^{i}\right] d F\left(\theta^{j}\right)
$$

Now $\frac{\partial \Pi^{i}\left(p\left(1, \theta^{j}\right), \theta\right)}{\partial \theta^{i}}=\left[p^{i}\left(1, \theta^{j}\right)-\frac{\partial c^{i}}{\partial x^{i}}\right] \frac{\partial x^{i}}{\partial q^{j}} \frac{\partial q^{j}}{\partial \theta^{i}}-\frac{\partial c^{i}}{\partial \theta^{i}}$. From total differentiation of

(21), $\frac{\partial q^{j}}{\partial \theta^{i}} \leq 0$. Therefore, $\frac{\partial \Pi^{i}\left(p\left(1, \theta^{j}\right), \theta\right)}{\partial \theta^{i}} \leq 0$ implying $h^{i}\left(1, \theta^{i}\right) \geq H^{i}(1)$. This

together with IC yields $H^{i}\left(\theta^{i}\right) \geq H^{i}(1)$ and so $H^{i}(1) \geq 0$ is equivalent to $I R$. 
Using (A2), the expected welfare measure $\mathrm{EW}$ can be rewritten as (A4)

$$
\begin{aligned}
\mathrm{EW}= & \mathrm{E}_{\theta}\left[\mathrm{S}(\mathrm{p}, \theta)-\alpha \sum \mathrm{H}^{\mathrm{i}}\left(\theta^{\mathrm{i}}\right)\right]=\int_{0}^{1} \int_{0}^{1}\left[S(p, \theta)-\alpha \sum H^{\mathrm{i}}\left(\theta^{\mathrm{i}}\right)\right] d F\left(\theta^{\mathrm{i}}\right) d F\left(\theta^{\mathrm{j}}\right)= \\
& \int_{\partial \theta}^{1}\left[S(p, \theta)-\alpha \sum \frac{F\left(\theta^{\mathrm{i}}\right)}{f\left(\theta^{\mathrm{i}}\right)}\left[\frac{\partial c^{\mathrm{i}}}{\partial q^{\mathrm{i}}} \frac{\partial q^{j}}{\partial \theta^{\mathrm{i}}}+\frac{\partial c^{\mathrm{i}}}{\partial \theta^{\mathrm{i}}}\right]\right] f\left(\theta^{\mathrm{i}}\right) f\left(\theta^{\mathrm{j}}\right) d \theta^{\mathrm{i}} d \theta^{\mathrm{j}}-\alpha \sum H^{\mathrm{i}}(1)
\end{aligned}
$$

where the last equality follows from integration by parts. Clearly, at the regulator's optimum $H^{i}(1)=0$. Therefore, part (ii) of Claim A1 together with (A4) yield part (i) of Claim 4, and part (i) of Claim A1 gives part (ii) of Claim 4.

QED

\section{Proof of Claim $5:$}

As before, let $\mathrm{h}^{\mathrm{i}}\left(\sigma^{\mathrm{i}}, \theta^{\mathrm{i}}\right)$ denote firm i's expected income,

$$
\mathrm{h}^{\mathrm{i}}\left(\sigma^{\mathrm{i}}, \theta^{\mathrm{i}}\right)=\mathrm{E}_{\theta^{\mathrm{j}}}\left\{\Pi^{\mathrm{i}}\left[\mathrm{x}^{\mathrm{i}}\left(\sigma^{\mathrm{i}}, \theta^{j}\right), \mathrm{p}^{\mathrm{i}}\left(\sigma^{\mathrm{i}}, \theta^{j}\right), \theta^{\mathrm{i}}\right]\right\}+\mathrm{T}^{\mathrm{i}}\left(\sigma^{\mathrm{i}}\right)
$$

and let $H^{i}\left(\theta^{i}\right)=h^{i}\left(\theta^{i}, \theta^{i}\right)$. The regulator's problem is

(A5) Choose functions $\mathrm{x}, \mathrm{p}$ and $\mathrm{T}$ to $\operatorname{maximize} \mathrm{E}_{\theta}[\mathrm{W}(\mathrm{x}(\theta), \mathrm{p}(\theta), \mathrm{T}(\theta), \theta)]$

$$
\text { Subject to }
$$

$$
h^{i}\left(\theta^{i}, \theta^{i}\right) \geq h^{i}\left(\sigma^{i}, \theta^{i}\right) \text { all } \theta^{i}, \sigma^{i}, i=0,1 .
$$

$$
h^{i}\left(\theta^{i}, \theta^{i}\right) \geq 0 \quad i=0,1 .
$$

The counterpart of Claim Al above is

Claim A2: (i) If $x, p$ and $T$ satisfy $I C$ and if $x$ and $p$ are piecewise continuous, then $\mathrm{H}^{\mathrm{i}}$ is differentiable almost everywhere and

$$
\mathrm{H}^{\mathrm{i}}(\eta)=\mathrm{H}^{\mathrm{i}}(1)+\int_{0}^{1} \int_{0}^{1} \frac{\partial c^{\mathrm{i}}}{\partial \theta^{\mathrm{i}}} d F\left(\theta^{\mathrm{j}}\right) d \theta^{\mathrm{i}}
$$

(ii) The IC constraint is equivalent to

$$
\int_{0}^{\eta} \int_{0}^{1} \frac{\partial c^{i}}{\partial \theta^{i}} d F\left(\theta^{j}\right) d \theta^{i} \geq\left.\int_{0}^{\eta} \int_{0}^{1} \frac{\partial c^{i}}{\partial \theta^{i}}\right|_{x=x\left(\eta, \theta^{j}\right), \mathrm{p}=\mathrm{p}\left(\eta, \theta^{j}\right)} d F\left(\theta^{j}\right) d \theta^{\mathrm{i}} \quad \text { for all } \eta \text { and } \nu .
$$

(iii) The IR constraint is equivalent to $H^{i}(1) \geq 0$. 
Proof of Claim A2: Part (i): The proof of this part is analogous to the proof of part (i) of Claim 4. It follows from the IC constraint that

$\mathrm{h}^{\mathrm{i}}(\eta, \eta)-\mathrm{h}^{\mathrm{i}}(\eta, \nu) \geq \mathrm{H}^{\mathrm{i}}(\eta)-\mathrm{H}^{\mathrm{i}}(\nu) \geq \mathrm{h}^{\mathrm{i}}(\nu, \eta)-\mathrm{h}^{\mathrm{i}}(\nu, \nu)$

Dividing through by $\eta-\nu$ and taking the limits of the RHS and LHS as $\nu$ approaches $\eta$ we get that where $x$ and $p$ are continuous at $\eta$, these limits are equal. Therefore, $\mathrm{H}^{\mathrm{i}}$ is differentiable at $\eta$ and the derivative is equal to these limits $\left.\frac{d H^{i}(\eta)}{d \eta}=-\int_{0}^{1}\left[\left(p^{i}-\frac{\partial c^{i}}{\partial x^{i}}\right) \frac{\partial y^{i}}{\partial q^{i}}-\frac{\partial c^{i}}{\partial q^{i}}\right] \frac{\partial q^{i}}{\partial \theta^{i}}+\frac{\partial c^{i}}{\partial \theta^{i}}\right] d F\left(\theta^{j}\right)=-\int_{0}^{1} \frac{\partial c^{i}}{\partial \theta^{i}} d F\left(\theta^{j}\right)$, where $y^{i}$ is defined in (24), $\mathrm{x}=\mathrm{x}\left(\eta, \theta^{\mathrm{j}}\right), \mathrm{q}=\mathrm{q}\left(\mathrm{x}, \mathrm{p}\left(\eta, \theta^{\mathrm{j}}\right), \eta, \theta^{\mathrm{j}}\right)$ and $\theta^{\mathrm{i}}=\eta$. The second equality in the above chain owes to $\left[\left(p^{i}-\frac{\partial c^{i}}{\partial x^{i}}\right) \frac{\partial y^{i}}{\partial q^{i}}-\frac{\partial c^{i}}{\partial q^{i}}\right] \frac{\partial q^{i}}{\partial \theta^{i}}=0$, which follows from the fact that $q^{i}$ maximizes $i$ 's profit. Expression (A6) is now obtained by integration.

Part (ii): The proof of this part is identical to that of part (ii) of Claim $A 1$, except that the references to (A2) and (A3) should be replaced by references to (A6) and (A7).

Part (iii): Since $\frac{\partial c^{i}}{\partial \theta^{i}} \geq 0, H^{i}$ is decreasing and hence the result.

Using the claim and integration by parts, the expected welfare measure EW can be rewritten as

$$
\begin{aligned}
\mathrm{EW} & =\mathrm{E}_{\theta}\left[\mathrm{S}(\mathrm{x}, \mathrm{p}, \theta)-\alpha \sum \mathrm{H}^{\mathrm{i}}\left(\theta^{\mathrm{i}}\right)\right]=\int_{0}^{1} \int_{0}^{1}\left[S(\mathrm{x}, \mathrm{p}, \theta)-\alpha \sum H^{\mathrm{i}}\left(\theta^{\mathrm{i}}\right)\right] d F\left(\theta^{\mathrm{i}}\right) d F\left(\theta^{\mathrm{j}}\right) \\
& =\int_{\theta}^{1}\left[S(\mathrm{x}, p, \theta)-\alpha \sum \frac{F\left(\theta^{\mathrm{i}}\right)}{f\left(\theta^{\mathrm{i}}\right)} \frac{\partial c^{\mathrm{i}}}{\partial \theta^{\mathrm{i}}}\right] f\left(\theta^{\mathrm{i}}\right) f\left(\theta^{\mathrm{j}}\right) d \theta^{\mathrm{i}} d \theta^{\mathrm{j}}-\alpha \sum H^{\mathrm{i}}(1)
\end{aligned}
$$

Clearly, at the regulator's optimum $H^{i}(1)=0$. Therefore, part (ii) of Claim A2 together with (A8) yield part (i) of Claim 5, and part (i) of Claim A2 gives part (ii) of Claim 5 . QED 


\section{Footnotes}

1. If the differentiation space is geographical, the implementation of the regulated monopolies regime involves the assignment of exclusive market areas; if it is some other characteristics space, the implementation of that regime involves quantity restrictions.

2. The public utility case does not fit exactly the present model, since distance does not affect directly consumers' utility but rather firms' costs.

3. Define $Q^{i}$ by $c_{2}^{i}\left(1, Q^{i}\right)=1$. The following conditions are sufficient for all the equilibria and the welfare optima to be interior: $c_{2}^{i}(x, 0)=0, V>2 t+c_{1}^{i}\left(1, Q^{i}\right)$ and $c_{1}(0,0)<t-Q^{i}+c_{1}^{i}\left(1, Q^{i}\right), i=0,1$. For appropriate choice of the parameters, these conditions are satisfied by the quadratic example analyzed in Section 6 .

4. The assumption on cost and demand together with $c_{22}>\left(1-2 c_{12}\right) / 4 t$ are sufficient for existence of such an equilibrium. Under these assumptions, i's profit function is concave in $\left(p^{i}, q^{i}\right)$. If we require $p^{i}, q^{i} \leq M<\infty$, then by a known theorem (see Theorem 3.1 in Friedman (1990)) this game has a Nash equilibrium in pure strategies. The conditions in footnote 3 imply that the equilibrium must be interior. It is immediate that, if $\mathrm{V}$ is large, this is still an equilibrium when $M=\infty$. Uniqueness of the equilibrium is not guaranteed.

5. When the two cost functions are the same, the allocations of profit maximum and surplus maximum coincide only if the total mass of consumers in [0,1/2] is the same as in $[1 / 2,1]$. But this of course need not be satisfied by an arbitrary uneven distribution of consumers over the interval.

6. In the product differentiation scenario the quantity is imposed rather than the specific assignment of the consumers, but it is still the case that the consumers served by firm $i$ are those who prefer its product more intensely.

7. Note that this function does not satisfy all of the technical assumptions we imposed earlier, but it still permits to solve the problems at hand.

8. Since $T^{i}$ enters directly only $i^{\prime} s$ payoff and the firms are expected profit maximizers, nothing is lost by assuming that $\mathrm{T}^{i}$ is a function of $\sigma^{i}$ alone.

9. In the first stage each firm reports its cost parameter and the regulation is implemented as in the full information case. Then the firms report $\left(\theta^{1}, \theta^{2}\right)$ simultaneously in the second stage. If these reports do not match, they are punished harshly; if these reports match and they indicate that $i$ lied in the first round, then $i$ is punished but not as heavily as when the reports do not match. An appropriate choice of punishments will clearly make truth telling an equilibrium.

10. Although some of the expressions derived with this example are rather cumbersome, it is difficult to imagine a simpler example which satisfies the model's assumptions and captures all the different points mentioned throughout. 


\section{References}

Anton, J, and P. Gertler (1994), "Regulation, Local Monopolies and Spatial Competition," mimeo, Duke University.

Anton, J. and D. Yao (1989), "Split Awards, Procurement and Innovation," RAND Journal of Economics, 30, $538-552$.

Auriol, E. and J.J. Laffont (1992), "Regulation by Duopoly," Working paper \#20 Institut $\mathrm{D}^{\prime}$ economie Industrielle.

Biglaiser, G. and A. Ma (1993), "Regulating A Dominant Firm: Quality, Private Information and Industry Structure," ISP discussion paper \#40, Boston University.

Friedman, J. (1990), Game Theory with Applications to Economics (2nd edition), Oxford University press.

Kamien, M. and D. Vincent(1991), "Price Regulation and Quality of Service," Discussion Paper 920, CMSEMS, Northwestern University.

Ma, A. and J. Burgess (1992), "Quality, Competition, Welfare and Regulation," mimeo, Boston University.

McGuire, T. and M. Riordan (1991), "Incomplete Information and Optimal Market Structure: Public Purchases from Public Providers," ISP discussion paper $\# 10$, Boston University.

Shleifer, A. (1985), "A Theory of Yardstick Competition," RAND Journal of Economics, $16,319-327$.

Spence, M. (1975), "Monopoly, Quality and Regulation," Bel1 Journal of Economics, Vo1. 6, No. 2, pp. 417-429. 